\title{
Determinants of Preterm Birth at the Postnatal Ward of Kenyatta National Hospital, Nairobi, Kenya
}

\author{
Okubatsion Tekeste Okube, Lillian Moraa Sambu \\ Regina Pacis Institute of Health Sciences, The Catholic University of Eastern Africa (CUEA), Nairobi, Kenya \\ Email: tekeste.ok@gmail.com
}

How to cite this paper: Okube, O.T. and Sambu, L.M. (2017) Determinants of Preterm Birth at the Postnatal Ward of Kenyatta National Hospital, Nairobi, Kenya. Open Journal of Obstetrics and Gynecology, 7, 973-988.

https://doi.org/10.4236/ojog.2017.79099

Received: August 14, 2017

Accepted: September 19, 2017

Published: September 22, 2017

Copyright $\odot 2017$ by authors and Scientific Research Publishing Inc. This work is licensed under the Creative Commons Attribution International License (CC BY 4.0).

http://creativecommons.org/licenses/by/4.0/

\begin{abstract}
Background: Preterm birth, delivery prior to 37 completed weeks or 259 days gestation, is a worldwide maternal and perinatal challenge and is a leading cause of neonatal morbidity and mortality. Preterm birth remains the leading cause of perinatal and postnatal mortality and morbidity especially in developing countries where the health care services are suffering from limited resources. Premature babies usually suffer from both immediate and long term consequences. Right after birth, they have difficulties in breathing, temperature regulation, bleeding, infection and other problems due to organ immaturity. Their growth and developmental milestones will also be affected leading poor physical, mental, educational and psychosocial problems as a long term consequences. Preterm deliveries were responsible for 1 million out of the 6.3 million deaths of children under 5 in 2013 [1]. In Kenyatta National hospital, few studies have been carried out to determine the prevalence and factors associated with preterm birth. Hence the aim of this study is to determine the prevalence and factors associated with preterm birth at Kenyatta national hospital (KNH), Nairobi, Kenya. Materials and Methods: This was a hospital based descriptive cross-sectional study involving randomly selected respondents $(\mathrm{N}=183)$ from post natal ward of Kenyatta National Hospital. Systematic random sampling method was applied to recruit the study respondents. A pre-tested semi-structured questionnaire was employed to collect information on the possible determinants of Preterm birth. Data was analysed using SPSS software version 22.0. Descriptive analysis was done using mean and frequency proportion. Inferential analysis using chi-square test was used to establish association different variables. The ethical approval to conduct the study was obtained from KNH-University of Nairobi Ethical Review Committee (KNH-UoN ERC). Permission to collect data was sought from the $\mathrm{KNH}$ and consent was obtained from the selected respondents before admin-
\end{abstract}


istering the questionnaire. Result: The prevalence rate of preterm birth was $20.2 \%$. History of urinary tract infection during pregnancy [AOR $=4.62 ; 95 \%$ $\mathrm{CI}=1.56-4.67 ; \mathrm{P}=0.013]$, history of preterm birth $[\mathrm{AOR}=5.8 ; 95 \% \mathrm{CI}=$ $1.18-10.30 ; \mathrm{P}=0.001$ ], history of abortion $[\mathrm{AOR}=3.54 ; 95 \% \mathrm{CI}=1.18-$ $10.41 ; \mathrm{P}=0.016]$, history of hypertension during pregnancy $[\mathrm{AOR}=2.04 ; 95 \%$ $\mathrm{CI}=1.14-3.64 ; \mathrm{P}=0.012]$, maternal age $(\geq 31$ years $)$ [AOR $=2.81 ; 95 \% \mathrm{CI}=$ 1.24 - 5.87; $\mathrm{P}=0.012$ ] and alcohol consumption during pregnancy [AOR = 2.56; $95 \% \mathrm{CI}=0.68-9.64 ; \mathrm{P}=0.014$ ] were determined as significant risk factors for preterm birth. Conclusion and recommendation: The determinants of preterm birth are multifactorial including history of abortion, preterm birth, urinary tract infection, hypertension and alcohol consumption during pregnancy. Most of these risk factors of preterm birth are controllable if reproductive age mothers are educated properly. It is very important for antenatal mothers to adhere to the guidelines of antenatal visits so that those at risk are spotted and close monitoring can done in order to reduce this high rate of preterm birth and its negative consequences. Strategies to avert the high prevalence of preterm birth and its associated morbidity and mortality must be given priority at national, regional and international levels, so that the Millennium Development Goal (MDG) 4 can be achieved.

\section{Keywords}

Prevalence, Preterm Birth, Risk Factors

\section{Introduction}

Preterm birth, birth before 37 completed weeks of pregnancy, is a global problem associated with high neonatal morbidity and mortality rates especially in developing countries. Globally, 15 million babies are born preterm each year and 1.1 million die as a result of complications [2]. The magnitude of preterm birth is particularly heavy for Africa and Asia where over 85 percent of all preterm births occur [3]. In developed countries, the prevalence of preterm birth was ranged from $5 \%$ to $7 \%$ and in African is estimated to be $11.9 \%$ of live births [4]. The national prevalence of preterm birth in 2010 for Kenya, Uganda, Ethiopia, Eritrea, Rwanda, Somalia and Sudan (East African Countries) was 12.3\%, 13.6\%, $10.1 \%, 12.2 \%, 9.5 \%, 12.0 \%, 13.2 \%$ respectively [5].

In spite of improvements in neonatal care, preterm birth is now the biggest single cause of death and long-term disability worldwide [1]. In 2015, the under-five mortality rate in low-income countries was 76 deaths per 1000 live births-about 11 times the average rate in high-income countries (7 deaths per 1000 live births) [6]. According to Kenya Demographic and Health Survey (KDHS, 2014), childhood deaths in Kenya was 52 deaths per every 1000 live births [7]. Comparing with developed countries, preterm babies born from developing counties face higher morbidity and mortality rates. In low-income set- 
tings, half of the babies born as a preterm die due to a lack of feasible, cost effective care, like provision of basic warmth, supporting breathing difficulties and taking preventive and control measures of infection. In high-income countries, almost all of these babies survive [8].

Although advances in prenatal and neonatal care have improved the survival for preterm infants, those infants who survive have an increased risk of death and morbidity during childhood as well as delay in both growth and development compared to babies born at term [9]. Children born prematurely have higher rates of learning disabilities, psychomotor problems and recurrent respiratory illnesses compared to children born at term [10]. Their growth and developmental milestones are negatively affected and often extend to later life, resulting in educational, psychological, social and medical problems. Preterm birth requires prolonged hospital stay after birth, frequent hospital admissions in the first year of life and increased risk of chronic lung disease [2] putting the parents in social and financial crisis.

Some of the perceived predisposing factors of preterm birth are: Having a previous premature birth, an interval of less than six months between pregnancies, multiple pregnancies, premature rapture of membranes, history of abortions, infections, smoking and alcohol intake during pregnancy and maternal diseases in pregnancy like hypertension and diabetes mellitus [11].

\section{Methods and Materials}

\subsection{Study Area}

The study was conducted at the postnatal ward of Kenyatta National Referral and Teaching Hospital which is located in the capital City of Nairobi. Kenyatta National Hospital (KNH) was founded in 1901 and covers an area of 45.7 hectares. It is the biggest public hospital in Kenya and offers a wide range of services including accident and emergency, obstetrics and gynecology, medical, surgical, orthopedics, oncology, and pediatrics, among others. It is the teaching hospital for University of Nairobi and other many universities.

\subsection{Study Design and Participants}

This was a descriptive cross-sectional study involving randomly selected respondents $(\mathrm{N}=183)$ from the post natal ward of Kenyatta National Hospital (KNH). The study population was all postnatal mothers who gave live birth during the study period at the Hospital. The sample size was determined by using Fischer's formula (Fischer et al., 1998); $\mathrm{n}=\mathrm{Z}^{2} \mathrm{pq} / \mathrm{d}^{2}$ ) by considering $95 \% \mathrm{CI}$ and degree of precision of 0.05 . The proportion of preterm birth was taken from the study carried out by Wagura, 2014 at $18.3 \%$. Accordingly the sample size would be 230 . However, since the target population during the study period was $<10,000$, sample size adjustment was done using the following formula. $\mathrm{nf}=\frac{\mathrm{n}}{1+\mathrm{n} / \mathrm{N}}$ resulting in 183 subjects. 


\subsection{Sampling Method}

During the study period, KNH labor ward served for 30 mothers daily, equivalent to 900 per month the period during which the data was collected. Systematic random sampling method was used to select study participants. The 900 mothers delivered in a month were divided by the minimum adjusted sample size (183) to get a sampling interval of 5 . The first mother to be included in the study was chosen randomly by blindly picking one of five pieces of paper named for the first five mothers in each day. After that, every fifth mother who gave birth was included in the sample until the desired sample size was attained.

\subsection{Data Collection}

Using a pre-tested semi structured questionnaire, the following data was collected from the postnatal mothers: Demographic and socio-economic characteristics, attendance of ANC clinic and taking IFAS, Obstetrics and gynecological related conditions, medical history, life style characteristics, health condition of the current pregnancy and dietary and cultural beliefs during pregnancy. Anthropometric measurements of the postnatal mothers are also taken to assess their nutritional status.

\section{Characteristics of the Newborn Babies}

Gestational age and anthropometric measurements (weight, height, head circumference and mid upper arm circumference (MUAC)) of the newborn were taken.

\subsection{Data Analyses}

The data was organized, screened and checked for completeness. Then it was coded and entered into the computer, and cross checked with the original data for accuracy. The data was analyzed using computer software (SPSS Ver. 22). The descriptive and inferential statistics were generated and reported appropriately. Specifically, data was descriptively analyzed into proportions and summarized in frequency tables. Chi Square test and odds ratio for bivariate analysis was used to establish the association of various variables and thereafter the significant variables were reassessed in the multiple logistics regression so as to identify the significant variables after controlling other confounding variables. The threshold for statistical significance was set at $\mathrm{p} \leq 0.05$. Variables having a $\mathrm{P}$-value $<0.05$ in the bivariate analysis were subjected into a multivariate analysis to determine factors significantly and independently predicting preterm birth.

\subsection{Ethical Consideration}

The ethical approval to conduct the study was obtained from Kenyatta National Hospital-University of Nairobi Ethical Review Committee (KNH-UoN-ERC) (Approval number: UP960/12/2016). The institutional permission was granted 
by the Department of Reproductive Health of the hospital. Consent was obtained from the subjects both verbally and in written before data collection. Mothers of premature babies were given health education how to handle their babies.

\section{Results}

\subsection{Socio-Demographic Characteristics of Respondents}

The respondents' (mothers) mean age was 26 with a SD of \pm 4.8 years. Of the respondents, nearly half, $49.2 \%$ aged 26 - 30 years followed by the age category of $18-25$ at $42.6 \%$. Few mothers were under 18 years old at $4.4 \%$ and above 30 years were at $3.8 \%$. Majority of the respondents, $86.9 \%$, were married while $9.8 \%$ and $3.3 \%$ were single and divorced respectively. Majority, $94 \%$, were Christian, $65.6 \%$ self-employed and $67.2 \%$ possessed secondary education (Table 1 ).

\subsection{Obstetric History of the Respondents}

Table 2 below shows the obstetric history of the respondents. The mean gestational age at delivery was 38.2 with a SD of \pm 2.5 weeks. The study found that the

Table 1. Socio-demographic characteristics of the respondents (mothers).

\begin{tabular}{|c|c|c|}
\hline Variables & $\mathbf{N}$ & Percent (\%) \\
\hline \multicolumn{3}{|c|}{ Age in years } \\
\hline$<18$ & 8 & 4.4 \\
\hline $18-25$ & 78 & 42.6 \\
\hline $26-30$ & 90 & 49.2 \\
\hline$\geq 31$ & 7 & 3.8 \\
\hline \multicolumn{3}{|c|}{ Marital status } \\
\hline Married & 159 & 86.9 \\
\hline Single & 18 & 9.8 \\
\hline Divorced & 6 & 3.3 \\
\hline \multicolumn{3}{|c|}{ Religion } \\
\hline Christian & 172 & 94 \\
\hline Muslim & 11 & 6 \\
\hline \multicolumn{3}{|c|}{ Occupation status } \\
\hline Self employed & 120 & 65.6 \\
\hline Government/private employee & 6 & 3.3 \\
\hline Housewife & 44 & 24 \\
\hline Student & 13 & 7.1 \\
\hline \multicolumn{3}{|c|}{ Level of education } \\
\hline Primary & 38 & 20.8 \\
\hline Secondary & 123 & 67.2 \\
\hline Tertiary & 22 & 12 \\
\hline
\end{tabular}


Table 2. Obstetric history of the respondents.

\begin{tabular}{|c|c|c|}
\hline Gestational age (weeks) at delivery & $\mathrm{N}$ & Percent (\%) \\
\hline$<37$ & 37 & 20.2 \\
\hline$\geq 37$ & 146 & 79.8 \\
\hline \multicolumn{3}{|c|}{ Parity } \\
\hline Para 1 & 36 & 19.7 \\
\hline Para 2 & 85 & 46.4 \\
\hline Para 3 & 48 & 26.2 \\
\hline Para 4 and above & 14 & 7.7 \\
\hline \multicolumn{3}{|c|}{ Inter-pregnancy interval (child space) } \\
\hline$\leq 2$ & 14 & 7.7 \\
\hline$>2$ & 133 & 72.6 \\
\hline Para 1 & 36 & 19.7 \\
\hline \multicolumn{3}{|c|}{ History of abortion } \\
\hline Yes & 14 & 7.7 \\
\hline No & 169 & 92.3 \\
\hline \multicolumn{3}{|c|}{ History of preterm birth } \\
\hline Yes & 30 & 16.4 \\
\hline No & 153 & 83.6 \\
\hline
\end{tabular}

prevalence of preterm birth was $20.2 \%$. Majority, $80.3 \%$, of the women were multigravida. Of the multigravida, 9.5\% (14) had an inter-pregnancy interval of 2 or less years. Majority, $92.3 \%$, of the respondents had a parity of less than 4 While $7.7 \%$ had parity of 4 and above. Few mothers, 14 (7.7\%), had a history of abortion. Out of the 14 respondents with history of abortion, 6 (42.9\%) gave preterm birth. Of the respondents, 30 (16.4\%) had a history of preterm birth. Mothers who had previous history of preterm birth had higher chances of delivering a preterm baby at $46.7 \%$ compared to those with no history of preterm birth at $15 \%$.

\subsection{Antenatal Clinic (ANC) Attendance of the Respondents}

The study found that 59\% of the mothers had attended ANC 3 - 4 times before delivery while $20.2 \%$ attended 1 - 2 times and $6 \%$ had never attended ANC. Generally $26.2 \%$ of the respondents attended ANC less than 3 times during their pregnancy (Table 3).

\subsection{Respondents' Acute and Chronic Health Conditions during Their Pregnancy}

Of the respondents, the prevalence of hypertension and diabetes was $18 \%$ and $3.8 \%$ respectively. Out of the 33 respondents with hypertension, 10 (30\%) gave preterm birth. Regarding to HIV status, majority, 166 (90.7\%), were negative 
Table 3. Respondents' gestational age at their first ANC attendance.

\begin{tabular}{ccc}
\hline Variables & N & Percent (\%) \\
\hline 12 weeks & Gestational age at first ANC attendance & \\
$12-18$ weeks & 4 & 2.2 \\
$19-24$ weeks & 36 & 19.7 \\
$25-32$ weeks & 99 & 54.1 \\
Not attended & 33 & 18 \\
& 11 & 6 \\
Never attended & Frequency of ANC attendance & 6 \\
$1-2$ times & 11 & 20.2 \\
$3-4$ Times & 37 & 59 \\
More than 4 times & 108 & 14.8 \\
\hline
\end{tabular}

while 17 (9.3\%) were positive. The prevalence of UTI and malaria among the study respondents was $30 \%$ and $10.4 \%$ respectively (Table 4 ).

\subsection{History of Alcohol Intake during Pregnancy}

Majority of the respondent, 168 (91.8\%), had no history of alcohol intake, while $15(8.2 \%)$ were using alcohol. Of the 15 respondents who had history of alcoholintake, 5 (33.3\%) deliver preterm babies.

\subsection{Nutritional Status of the Respondents}

Body Mass Index (BMI) and Hemoglobin (HB) levels.

Of the respondents, 73 (39.9\%) had a normal (18.5 - 24.9) BMI. Few mothers, 17 (9.3\%), had a BMI less than 18.5. About one third, 63 (34.4\%) had a BMI of 25 - 29.9 while $30(16.4 \%)$ had a BMI of above 30 . Among the 183 respondents, 169 (92.3\%) had a HB level of $10-13 \mathrm{mg} / \mathrm{dl}$ while $14(7.7 \%)$ had a BH level of less than 10 (Table 5).

\subsection{Characteristics of the Newborn}

Most, 94 (51.4\%) were males and 89 (48.6\%) were females. Majority, 146 (79.8\%) of the babies born at term ( $\geq 37$ weeks) while 37 (20.2\%) were born as preterm, before 37 weeks of gestation. Therefore, the prevalence of preterm birth was $20.2 \%$. The prevalence of preterm birth was higher among male babies $(73 \%$ vs 27\%). Of those who born as preterm, 8 (4.4\%) were born between 22 - 26 weeks gestation while $13(7.1 \%)$ were born between 27 - 31 weeks of gestation and 16 (8.7\%) were born between 32 - 36 weeks of gestation. Majority, $95.1 \%$, of the babies born as a singleton and $9(4.9 \%)$ were twins. The prevalence of low birth weight ( $<2500 \mathrm{~g}$ ) was $21.9 \%$ (Table 6 ). 
Table 4. Acute and chronic health conditions of the mothers during pregnancy.

\begin{tabular}{|c|c|c|}
\hline Variables & $\mathbf{N}$ & Percent (\%) \\
\hline \multicolumn{3}{|c|}{ Diabetes } \\
\hline Yes & 7 & 3.8 \\
\hline No & 176 & 96.2 \\
\hline \multicolumn{3}{|c|}{ Hypertension } \\
\hline Yes & 33 & 18 \\
\hline No & 150 & 82 \\
\hline \multicolumn{3}{|c|}{ HIV status of the women } \\
\hline Sero-positive & 17 & 9.3 \\
\hline Sero-negative & 166 & 90.7 \\
\hline \multicolumn{3}{|c|}{ Urinary tract infection } \\
\hline Yes & 55 & 30 \\
\hline No & 128 & 70 \\
\hline \multicolumn{3}{|c|}{ Malaria } \\
\hline Yes & 19 & 10.4 \\
\hline No & 164 & 89.6 \\
\hline
\end{tabular}

Table 5. Body Mass Index (BMI) and Haemoglobin (HB) level of respondents (mothers).

\begin{tabular}{ccc}
\hline Variables & N & Percent (\%) \\
\hline 18.5 & BMI & \\
$18.5-24.9$ & 17 & 9.3 \\
$25-29.9$ & 73 & 39.9 \\
$\geq 30$ & 63 & 34.4 \\
Haemoglobin (HB) level of the respondents $(\mathrm{mg} / \mathrm{dl})$ & 16.4 \\
$10-13$ & 169 & 92.3 \\
Less than 10 & 14 & 7.7 \\
\hline
\end{tabular}

\subsection{Factors Associated with Preterm Birth Using Bivariate Analysis}

Respondents' age, marital status, being a student, frequency of ANC attendance, alcohol consumption during pregnancy, Hypertension during pregnancy, History of abortion, History of preterm birth, Urinary tract infection during pregnancy and Inter-pregnancy interval (child space) were significantly associated with preterm birth. However, following multivariate analysis maternal age, hypertension during pregnancy, history of abortion, history of preterm birth, urinary tract infection during pregnancy and alcohol consumption during pregnancy remained significantly and independently determinants of preterm birth. 
Table 6. Characteristics of the newborn.

\begin{tabular}{|c|c|c|}
\hline Variables & $\mathbf{N}$ & Percent (\%) \\
\hline \multicolumn{3}{|c|}{ Gender of the newborn babies } \\
\hline Male & 94 & 51.4 \\
\hline Female & 89 & 48.6 \\
\hline Singleton & 174 & 95.1 \\
\hline Twins & 9 & 4.9 \\
\hline \multicolumn{3}{|c|}{ Gestational age (weeks) } \\
\hline $22-26$ & 8 & 4.4 \\
\hline $27-31$ & 13 & 7.1 \\
\hline $32-36$ & 16 & 8.7 \\
\hline$\geq 37$ & 146 & 78.8 \\
\hline \multicolumn{3}{|c|}{ Birth weight (g) } \\
\hline $1000-1500$ & 11 & 6.0 \\
\hline $1500-1999$ & 17 & 9.3 \\
\hline $2000-2499$ & 12 & 6.6 \\
\hline $2500 \mathrm{~g}$ and above & 143 & 78.1 \\
\hline
\end{tabular}

Mothers in the age group of 31 years and above had significantly higher likelihood of delivering a preterm baby $[\mathrm{AOR}=2.81 ; 95 \% \mathrm{CI}=1.24-5.87 ; \mathrm{P}=$ 0.012] compared to respondents aged 31 years and below.

Respondents with history of abortion had a 3.5-fold increased chance of delivering a preterm baby $[\mathrm{AOR}=3.54 ; 95 \% \mathrm{CI}=1.18-10.41 ; \mathrm{P}=0.016]$ compared to mothers with no history of abortion. Mothers who had history of preterm birth were about 6 times more at risk to deliver a preterm baby [AOR $=5.8 ; 95 \%$ $\mathrm{CI}=1.18-10.30 ; \mathrm{P}=0.001]$ compared to those mothers had no history of preterm birth. Hypertensive mothers were two times more likely to give preterm birth $[\mathrm{AOR}=2.04 ; 95 \% \mathrm{CI}=1.14-3.64 ; \mathrm{P}=0.012]$ than mothers without hypertension. Urinary tract infection during pregnancy was also a significant risk factor for preterm birth. Mothers with history urinary tract infection during pregnancy were more than 4 times more likely to give preterm birth [AOR = 4.62; $95 \% \mathrm{CI}=1.56-4.67 ; \mathrm{P}=0.013]$ than mothers without history of urinary tract infection during pregnancy. Mothers with history alcohol consumption during pregnancy were more than 2.5 times at risk of delivering a preterm birth $[\mathrm{AOR}=2.56 ; 95 \% \mathrm{CI}=0.68-9.64 ; \mathrm{P}=0.014]$ compared to mothers with no history of alcohol consumption (Table 7).

\section{Discussion}

The prevalence of preterm birth in the current study was $20.2 \%$, which is much higher than the Kenya National prevalence rate at $12.3 \%$ in 2010 [5]. It is also higher than the rates reported for African prevalence at 11.9\% [4], Nigeria find- 
Table 7. Factors associated with preterm birth using unadjusted and adjusted logistic regression.

\begin{tabular}{|c|c|c|c|c|}
\hline Variables & Preterm, n (\%) & Term, $\mathrm{n}(\%)$ & COR $(95 \% \mathrm{CI})$ & AOR $(95 \% \mathrm{CI})$ \\
\hline \multicolumn{5}{|c|}{ Age in years } \\
\hline$<18$ & $2(25 \%)$ & $6(75 \%)$ & Reference & Reference \\
\hline $18-30$ & $33(19.6 \%)$ & $135(80.4 \%)$ & $1.64(0.54-1.60)$ & $1.64(0.54-1.60)$ \\
\hline$\geq 31$ & $2(28.6 \%)$ & $5(71.4 \%)$ & $2.37(1.12-4.70)$ & $2.81(1.24-5.87)^{*}$ \\
\hline \multicolumn{5}{|c|}{ Marital status } \\
\hline Married & $31(19.5 \%)$ & $128(80.5 \%)$ & Reference & Reference \\
\hline Single & $5(27.8 \%)$ & $13(72.2 \%)$ & $1.59(0.88-2.55)$ & $2.20(0.86-4.65)$ \\
\hline Divorced & $1(16.7 \%)$ & $5(83.3 \%)$ & $0.82(0.44-1.77)$ & $0.83(0.44-1.77)$ \\
\hline \multicolumn{5}{|c|}{ Religion } \\
\hline Christian & $36(20.9 \%)$ & $136(79.1 \%)$ & $2.65(1.38-5.17)$ & $2.00(0.86-4.65)$ \\
\hline Muslim & $1(9.1 \%)$ & $10(90.9 \%)$ & Reference & Reference \\
\hline \multicolumn{5}{|c|}{ Occupation status } \\
\hline Self employed & $26(21.7 \%)$ & $94(78.3 \%)$ & $1.75(0.88-2.55)$ & \\
\hline Government/private employee & $1(16.7 \%)$ & $5(83.3 \%)$ & $1.27(0.47-3.15)$ & \\
\hline Student & $4(30.8 \%)$ & $9(69.2 \%)$ & $2.81(1.06-8.23)$ & $2.34(0.64-5.88)$ \\
\hline Housewife & $6(13.6 \%)$ & $38(86.4 \%)$ & Reference & Reference \\
\hline \multicolumn{5}{|c|}{ Level of education } \\
\hline Primary & $9(23.7 \%)$ & $29(76.3 \%)$ & & \\
\hline Secondary & $21(17.1 \%)$ & $102(82.9 \%)$ & & \\
\hline \multirow[t]{2}{*}{ Tertiary } & $7(31.8 \%)$ & $15(68.2 \%)$ & & \\
\hline & & Parity & & \\
\hline$\leq 3$ & $34(20.1 \%)$ & $135(79.9 \%)$ & Reference & \\
\hline$\geq 4$ & $3(21.4 \%)$ & $11(78.6 \%)$ & $1.08(0.50-2.12)$ & \\
\hline \multicolumn{5}{|c|}{ Inter-pregnancy interval (child space) } \\
\hline$\leq 2$ years & $6(42.9 \%)$ & $8(57.1 \%)$ & $3.41(1.06-10.06)$ & $2.68(0.82-8.75)$ \\
\hline$>2$ years & $24(18.1 \%)$ & $109(81.9 \%)$ & Reference & Reference \\
\hline Para 1 & $7(19.4 \%)$ & $29(80.6 \%)$ & $1.09(0.50-2.12)$ & \\
\hline \multicolumn{5}{|c|}{ History of abortion } \\
\hline Yes & $6(42.9 \%)$ & $8(57.1 \%)$ & $3.34(1.07-10.06)$ & $3.54(1.18-10.41)^{* *}$ \\
\hline No & $31(18.3 \%)$ & $138(81.7 \%)$ & Reference & Reference \\
\hline \multicolumn{5}{|c|}{ History of preterm birth } \\
\hline Yes & $14(46.7 \%)$ & $16(53.3 \%)$ & $4.95(1.06-10.06)$ & $5.8(1.18-10.30)^{\star * *}$ \\
\hline No & $23(15.0 \%)$ & $130(85.0 \%)$ & Reference & Reference \\
\hline
\end{tabular}




\section{Continued}

Never attended
1 - 2 times
3 - 4 Times

More than 4 times

Yes
No
Yes
No

Sero-positive

Sero-negative

Yes

Yes

$18.5-24.9$
$<18.5$
$25-29.9$
$\geq 30$

$$
\geq 30
$$$$
<10
$$$$
\geq 10
$$

Yes

No

$$
\begin{aligned}
& 2(18.2 \%) \\
& 15(40.5 \%) \\
& 18(16.7 \%)
\end{aligned}
$$$$
2(7.4 \%)
$$$$
0(0.0 \%)
$$$$
37(21.1 \%)
$$

$10(30.3 \%)$

$27(18.0 \%)$

$$
4(23.5 \%)
$$

$33(19.9 \%)$ U)
$21(38.2 \%)$
$16(12.5 \%)$

$2(10.5 \%)$

$35(21.3 \%)$

Body Mass Index (BMI) of the women

$\begin{array}{lcc}18(24.7 \%) & 55(75.3 \%) & \text { Reference } \\ 4(23.5 \%) & 13(76.5 \%) & 0.94 \\ 10(15.9 \%) & 53(84.1 \%) & 0.58 \\ 5(16.7 \%) & 25(83.3 \%) & 0.61\end{array}$

Haemoglobin (HB) level of the respondents (mg/dl)

$3(21.4 \%)$

$34(20.1 \%)$

\begin{abstract}
$11(78.6 \%)$
\end{abstract}
135 (79.9\%)

$1.08(0.61-1.92)$

Reference

Alcohol consumption during pregnancy

$\begin{array}{ccc}5(33.3 \%) & 10(66.7 \%) & 2.13(0.56-8.19) \\ 32(19.0 \%) & 136(81.0 \%) & \text { Reference }\end{array}$

$2.78(1.38-5.17)$

$8.52(1.06-10.06)$

Reference

Reference

$1.24(0.73-2.06)$

Reference

0.43

Reference

ference

61

HIV status of the women

Malaria infection during pregnancy

$\begin{array}{ccc}23(69.7 \%) & 1.98(1.11-3.31) & 2.04(1.14-3.64)^{*} \\ 123(82.0 \%) & \text { Reference } & \text { Reference }\end{array}$

$\begin{array}{cc}4.32(1.25-4.30) & 4.62(1.56-4.67)^{* *} \\ \text { Reference } & \text { Reference }\end{array}$


The study determined that advanced maternal age ( $\geq 31$ years) were significantly at risk of delivering a preterm compared to those mothers below 31 years. This finding agrees with studies done in Nigeria [12], Tanzania [14] and other study [15] which found that advanced maternal age was significantly and independently increased the risk of preterm birth. Mothers in their advanced age ( $\geq 35$ years), become weak and the uterine environment become less favorable for the growing fetus to provide maximum requirements thus predisposes them to be born before the due date. It is also the uterine muscles become weak to hold pregnancy to term. Moreover, old mothers $(\geq 35)$ are also at risk of having preterm deliveries because they are more likely to have other chronic conditions (such as high blood pressure and diabetes) that can cause complications requiring preterm delivery.

History of abortion is another significant risk factor associated with preterm birth. Respondents with history of abortion had 3.5 increased odds of preterm delivery than those with no such history. This finding is in agreement with multiple studies conducted in different regions of the world such as in Ethiopia [13], Tanzania [14], Canada [16] and others [17] [18] [19] [11]. The fact that abortion increase the risk of preterm birth is that surgical evacuation of the uterus mechanically stretches the cervix which predisposes such mothers to preterm birth in the consecutive pregnancies. The chance of delivering a preterm birth was significantly higher among mothers who had history of preterm birth compared to those mothers with no history of preterm birth. This finding correlates to the findings of Ethiopia [13], Tanzania [14], Malawi [20]; Iran [21], German [22] and others [19] [11]. The repetition risk in women with a previous preterm delivery ranges from $15 \%$ to more than $50 \%$ depending on the number and gestational age of previous deliveries [23]. The mechanism for this has not been well understood, however, the likelihood of such experience among the women with prior spontaneous labor as well as those with inducing preterm birth is rising.

In this study, urinary tract infection (UTI) during pregnancy was a significant risk factor for preterm birth. Mothers who had history of UTI were more than 4 times prone to deliver a preterm baby compared to mothers with no history of UTI. This result supports or agrees with previous findings of Ethiopia [13], Nigeria [24] and Iran [21]. Infection in the urinary system may raise release of inflammatory chemokine's and cytokines such as interleukins and tumor necrosis factors. Microbial Endotoxins and pro-inflammatory cytokines stimulate the production of prostaglandins (other inflammatory mediators) and matrix-degrading enzymes that finally result in stimulation of uterine contractions, preterm rupture of the membrane, and preterm birth [25].

The study revealed that hypertension during pregnancy was a significant risk factor for preterm birth. This result is in line with studies carried out in Ethiopia [13] [26] Nigeria [12] and Iran [21] who found that hypertension as a significant risk factor for preterm birth. Hypertension during pregnancy greatly reduces placental blood flow and leads to fetal restriction and poor growth resulting in 
obstetric emergencies which requires surgical delivery or induced preterm delivery as a lifesaving measure for both the mother and the fetus. Placental abruption, separation of the placenta from the wall of the uterus before birth, is another complication of hypertension that requires termination of pregnancies. Reduced placental blood flow in hypertensive pregnant women decreases fetal growth, with an increased risk of intrauterine growth restriction leads either low birth weight or premature birth [27]. Therefore, disorders like placenta abruption and pre-eclampsia causes intrauterine growth restriction may results in surgical operations and preterm birth [25].

The study also found that alcohol consumption during pregnancy was another significant risk factor for preterm birth. The proportion of preterm birth was significantly higher (2.5 times) among mothers who had history of alcohol consumption compared to mothers with no history of alcohol consumption. This finding agrees with several findings [28] [29] [30] [31] [32] who found that alcohol consumption during pregnancy increases the risks of preterm birth. In pregnant women, alcohol can precipitate preterm labor [31] and in the first trimester may also increase the risk of spontaneous abortion by as much as 4 -fold [33]. However, to the best our knowledge, there is no clear explanation how alcohol consumption during pregnancy contributes to preterm birth.

\section{Conclusion}

The study determined that the prevalence of preterm birth is high at $20.2 \%$. Advanced maternal age, hypertension, history of preterm birth, history of abortion, urinary tract infection and alcohol consumption during pregnancy were significantly and independently associated with preterm birth. Appropriate strategies targeting to these identified factors should develop at the national, regional and international levels and implement at the communities level so that the high rate of preterm birth can be decreased. Extensive health education and awareness campaigns at the community setting may decrease the rate of preterm birth and its negative consequences so that MGD- 4 can be achieved.

\section{Acknowledgements}

The authors are grateful for all study participants who took part in the study for their time.

\section{Conflict of Interest}

The authors have no conflict of interest.

\section{References}

[1] Liu, L., Oza, S., Hogan, D., Perin, J., Rudan, I., Lawn, J.E., Cousens, S., Mathers, C. and Black, R.E. (2015) Global, Regional, and National Causes of Child Mortality in 2000-2013, with Projections to Inform Post-2015 Priorities: An Updated Systematic Analysis. Lancet, 385, 430-440. https://doi.org/10.1016/S0140-6736(14)61698-6

[2] WHO (2012) Born Too Soon. The Global Action Report on Preterm Birth. World 
Health Organization, Geneva.

[3] March of Dimes (2009) White Paper on Preterm Birth. The Global and Regional Toll, White Paper, New York.

[4] Beck, S., Wojdyla, D., Say, L., Bertran, A.P., Meraldi, M., et al. (2010) The Worldwide Incidence of Preterm Birth: A Systematic Review of Maternal Mortality and Morbidity. Bull World Health Organization, 88, 31-38. https://doi.org/10.2471/BLT.08.062554

[5] The Global Action Report on Preterm Birth (2010) Preterm Rate and Births Data. In: Blencowe, H., Cousens, S., Oestergaard, M.Z., Chou, D., Moller, A.-B., Narwal, R., Adler, A., Garcia, C.V., Rohde, S.S., Say, L. and Lawn, J.E., Eds., National, Regional and Worldwide Estimates of Preterm Birth Rates in the Year 2010 with Time Trends for Selected Countries Since 1990: A Systematic Analysis and Implications, Estimates for World Health Organization, Geneva.

[6] World Health Organization (2017) Global Health Observatory (GHO) Data. Child Mortality and Causes of Death. World Health Organization, Geneva.

[7] Kenya Demographic and Health Survey (KDHS) (2014) Kenya National Bureau of Statistics, Ministry of Health Nairobi, Kenya.

[8] Blencowe, H., Cousens, S., Oestergaard, M.Z., et al. (2012) National, Regional, and Worldwide Estimates of Preterm Birth Rates in the Year 2010 with Time Trends Since 1990 for Selected Countries: A Systematic Analysis and Implications. Lancet, 379, 2162-2172. https://doi.org/10.1016/S0140-6736(12)60820-4

[9] Gladstone, M., Neilson, J.P., White, S., Kafulafula, G. and van den Broek, N. (2011) Post Neonatal Mortality, Morbidity, and Developmental Outcome after Ultrasound Dated Preterm Birth in Rural Malawi: A Community-Based Cohort Study. PLOS Medicine, 8, Article ID: e1001121. https://doi.org/10.1371/journal.pmed.1001121

[10] IOM (Institute of Medicine) (2007) Preterm Birth. Causes, Consequences, and Prevention. Institute of Medicine, National Academies of Sciences. National Academies Press, Washington DC.

[11] Fraser, D.M. and Cooper, M.A. (2008) Myles Textbook for Midwives. Churchill, Livingstone, London, Edinburgh.

[12] Butali, A., Ezeaka, C., Ekhaguere, O., Weathers, N., Ladd, J., Fajolu, I., Esezobor, C., Makwe, C., Odusanya, B., Anorlu, R., Adeyemo, W., Iroha, E., Egri-Okwaji, M., Adejumo, P., Oyeneyin, L., Abiodun, M., Badejoko, B. and Ryckman, K. (2016) Characteristics and Risk Factors of Preterm Births in a Tertiary Center in Lagos, Nigeria. Pan African Medical Journal, 24, 1. https://doi.org/10.11604/pamj.2016.24.1.8382

[13] Bekele, I., Demeke, T. and Dugna, K. (2017) Prevalence of Preterm Birth and Its Associated Factors among Mothers Delivered in Jimma University Specialized Teaching and Referral Hospital, Jimma Zone, Oromia Regional State, South West Ethiopia. Women's Health Care Journal, 6, 356.

[14] D’Cruz, R. and Harding, K. (2012) Investigating Risk Factors for Preterm Birth in Rural Tanzania: A Case-Control Study. Archives of Disease in Childhood-Fetal and Neonatal Edition, 97, A112. https://doi.org/10.1136/fetalneonatal-2012-301809.365

[15] Schure, V., Voigt, M., Schild, R., et al. (2012) Perinatal Risks in "Late Motherhood" Defined Based on Parity and Preterm Birth Rate-An Analysis of the German Perinatal Survey (20th Communication). Geburtshilfe Und Frauenheilkunde, 72, 49-55. https://doi.org/10.1055/s-0031-1280407

[16] Hardy, G., Benjamin, A. and Abenhaim, H.A. (2013) Effect of Induced Abortions 
on Early Preterm Births and Adverse Perinatal Outcomes. Journal of Obstetrics and Gynaecology Canada, 35, 138-143. https://doi.org/10.1016/S1701-2163(15)31018-5

[17] Freak-Poli, R., Chan, A., Tucker, G., et al. (2009) Previous Abortion and Risk of Pre-Term Birth: A Population Study. Journal of Maternal-Fetal and Neonatal Medicine, 22, 1-7. https://doi.org/10.1080/14767050802531813

[18] Gagnon, A.J., Zimbeck, M., Zeitlin, J., et al. (2009) Migration to Western Industrialised Countries and Perinatal Health: A Systematic Review. Social Science \& Medicine, 69, 934-946. https://doi.org/10.1016/j.socscimed.2009.06.027

[19] Heaman, M., Kingston, D., Chalmers, B., et al. (2013) Risk Factors for Preterm Birth and Small-For-Gestational-Age Births among Canadian Women. Paediatric and Perinatal Epidemiology, 27, 54-61. https://doi.org/10.1111/ppe.12016

[20] Nynke, R., van den Broek, Jean-Baptiste, R. and Neilson, J.P. (2014) Factors Associated with Preterm, Early Preterm and Late Preterm Birth in Malawi.

[21] Alijahan, R., Hazrati, S., Mirzarahimi, M., Pourfarzi, F. and Hadi, P.A. (2014) Prevalence and Risk Factors Associated with Preterm Birth in Ardabil, Iran. Iranian Journal of Reproductive Medicine, 12, 47-56.

[22] Ahumada-Barrios, M.E. and Alvarado, G.F. (2016) Risk Factors for Premature Birth in a Hospital. Revista Latino-Americana de Enfermagem, 24, e2750. https://doi.org/10.1590/1518-8345.0775.2750

[23] Goldenberg, R.L., Culhane, J.F., Iams, J.D. and Romero, R. (2008) Epidemiology and Causes of Preterm Birth. Lancet, 371, 75-84. https://doi.org/10.1016/S0140-6736(08)60074-4

[24] Mahmoodi, Z., Hoseini, F., Sadeghi Avval Shahr, H., Ghodsi, Z. and Amini, L. (2010) The Association between Maternal Factors and Preterm Birth and Premature Rapture of Membranes. Journal of Family Planning and Reproductive Health, 4, 135-139.

[25] Cunningham, F.G., Leveno, K.J. and Hauth, J.C., Eds. (2010) Williams Obstetrics. 23rd Edition, McGraw Hill, New York.

[26] Gebreslasie, K. (2016) Preterm Birth and Associated Factors among Mothers Who Gave Birth in Gondar Town Health Institutions. Advances in Nursing, 2016, Article ID: 4703138,5 .

[27] Sivakumar, S., Vishnu Bhat, B. and Badhe, B.A. (2007) Effect of Pregnancy Induced Hypertension on Mothers and Their Babies. Indian Journal of Pediatrics, 74, 623-625. https://doi.org/10.1007/s12098-007-0110-2

[28] Sokol, R.J., Janisse, J.J., Louis, J.M., et al. (2007) Extreme Prematurity: An Alcohol-Related Birth Effect. Alcoholism: Clinical and Experimental Research, 31, 1031-1037. https://doi.org/10.1111/j.1530-0277.2007.00384.x

[29] Aliyu, M.H., Lynch, O., Belogolovkin, V., et al. (2010) Maternal Alcohol Use and Medically Indicated vs. Spontaneous Preterm Birth Outcomes: A Population-Based Study. European Journal of Public Health, 20, 582-587. https://doi.org/10.1093/eurpub/ckq036

[30] Avalos, L.A., Kaskutas, L., Block, G., et al. (2011) Does Lack of Multinutrient Supplementation during Early Pregnancy Increase Vulnerability to Alcohol-Related Preterm or Small-For-Gestational-Age Births? Maternal and Child Health Journal, 15, 1324-1332. https://doi.org/10.1007/s10995-010-0690-8

[31] Patra, J., Bakker, R., Irving, H., et al. (2011) Dose-Response Relationship between Alcohol Consumption before and during Pregnancy and the Risks of Low Birthweight, Preterm Birth and Small for Gestational Age (SGA) - A Systematic Review 
and Meta-Analyses. BJOG, 118, 1411-1421.

https://doi.org/10.1111/j.1471-0528.2011.03050.x

[32] Miyake, Y., Tanaka, K., Okubo, H., Sasaki, S. and Arakawa, M. (2014) Alcohol Consumption during Pregnancy and Birth Outcomes: The Kyushu Okinawa Maternal and Child Health Study. BMC Pregnancy and Childbirth, 14, 79.

http://www.biomedcentral.com/1471-2393/14/79 https://doi.org/10.1186/1471-2393-14-79

[33] Rasch, V. (2003) Cigarette, Alcohol, and Caffeine Consumption: Risk Factors for Spontaneous Abortion. Acta Obstetricia et Gynecologica Scandinavica, 82, 182-188. https://doi.org/10.1034/j.1600-0412.2003.00078.x

\section{Abbreviations}

ANC: Antenatal care;

AOR: Adjusted odds ratio;

CI: Confidence interval;

COD: Crude odds ratio;

KNH: Kenyatta National Hospital;

OR: Odds ratio;

SPSS: Statistical package for social science;

WHO: World Health Organization;

UON: University of Nairobi;

IOM: Institute of Medicine.

Submit or recommend next manuscript to SCIRP and we will provide best service for you:

Accepting pre-submission inquiries through Email, Facebook, LinkedIn, Twitter, etc. A wide selection of journals (inclusive of 9 subjects, more than 200 journals)

Providing 24-hour high-quality service

User-friendly online submission system

Fair and swift peer-review system

Efficient typesetting and proofreading procedure

Display of the result of downloads and visits, as well as the number of cited articles

Maximum dissemination of your research work

Submit your manuscript at: http://papersubmission.scirp.org/

Or contact ojog@scirp.org 